Cell Research (2002); 12(2):117-121

http://www.cell-research.com

\title{
Cytopathological evaluations combined RNA and protein analyses on defined cell regions using single frozen tissue block
}

\author{
Hong LI*, XIAO YAN CHEN, QING You KONG, JiA LIU \\ Laboratory of Cell Biology and Molecular Genetics, College of Basic Medical Sciences, Dalian Medical University, \\ Dalian 116027, China
}

\begin{abstract}
The co-existence of multiple cell components in tissue samples is the main obstacle for precise molecular evaluation on defined cell types. Based on morphological examination, we developed an efficient approach for paralleled RNA and protein isolations from an identical histological region in frozen tissue section. The RNA and protein samples prepared were sufficient for RT-PCR and Western blot analyses, and the results obtained were well coincident each other as well as with the corresponding parameters revealed from immunohistochemical examinations. By this way, the sampling problem caused by cell-cross contamination can be largely avoided, committing the experimental data more specific to a defined cell type. These novel methods thus allow us to use single tissue block for a comprehensive study by integration of conventional cytological evaluations with nucleic acid and protein analyses.
\end{abstract}

Key words: RNA and protein preparation, defined histological region, serial frozen section, gene expression.

\section{INTRODUCTION}

In RNA and protein studies, the existence of multiple cell components in tissue specimens remains an annoying issue in the attempt to correlate the results to an identical cell type. Furthermore, the conventional RNA and protein preparations do not allow the use of one tissue block for multiple experimental purposes. Since the cell components are variable even in the same specimen, it is sometimes difficult to judge the results, especially the quantitative ones, obtained from different blocks. It is therefore necessary to develop a reliable and more efficient technique by which paralleled RNA and protein isolations as well as multiple analyses on the serial frozen sections can be performed on the defined histological region(s) with the same tissue block.

* Corresponding author: Dr. Hong Li. Tel/Fax: +86 411 4721202; Email: lihongmcn@Yahoo.com.cn

Received Nov-8-2001 Revised Jan-28-2002 Accepted March-282002

\section{MATERIALS AND METHODS}

\section{Surgical specimens}

Gastric cancer specimens were collected from the Department of Surgical Oncology of our Affiliated Hospital within 1 hour after removal. After careful pathological examination, the tissue blocks from six representative cases with heterogeneous morphological compositions were chosen for further analyses. The manner of sample collection and treatment was the same as described previously[1].

\section{Serial frozen section for multiple evaluations}

The frozen tissue blocks were sectioned serially in $5 \mathrm{~mm}$ thickness and fixed in ice-cold acetone for $20 \mathrm{~min}$. One slide was used for pathological determination by $\mathrm{H}$ and $\mathrm{E}$ staining, and the next ones for immunocytochemical staining (ICC) of the target gene products, such as the Receptor of hyaluronic acid mediated motility (RHAMM) demonstrated in this study. According to the morphological observation and ICC results, the defined histological regions were selected from the tissue block respectively, and then subjected to RNA and protein preparations by the methods described below.

Immunocytochemical staining (ICC)

The anti-human RHAMM antiserum was generously provided 
Comprehensive analyses with single tissue block

by Dr. Assmann V (Imperial Cancer Research Fund Laboratory, St. Thomas' Hospital, London, UK). It was generated by immunization of rabbits with a recombinant RHAMM protein was used for RHAMM immunocytochemical staining[2]. The staining was done by the procedures described elsewhere[3]. Bindings of the antibodies were detected by a peroxidase color reaction using 3,3diaminobenzidine tetrahydrochloride (DAB) as substrate.

\section{Sample Collection from defined region in frozen sections}

According to the histological observation and the results of RHAMM ICC staining, the pieces of target histological region were isolated from the frozen sections firstly for RNA and then for protein preparation. Briefly, referring to the histological observation, the border of selected region in the cross section of the frozen specimen was marked gently with an autoclaved surgical knife. According to the size of the interested region, two to four pieces of $10 \mu \mathrm{m}$ serial sections were made for RNA preparation and eight to sixteen pieces for protein preparation. The target tissues were collected with an autoclaved piped-tip and put immediately into pre-chilled buffers for RNA or protein isolation.

\section{Quick RNA preparation and RT-PCR analysis}

The collected sample pieces were put into $20 \mu \mathrm{l}$ RA sample buffer containing 1.25 X PCR buffer, 5 U RNasin, 1U RQ1 RNasefree DNase and $2 \mathrm{mM}$ dithiothreitol (DTT). To lyse the cells well, the sample-containing tubes were snap frozen in $-80^{\circ} \mathrm{C}$ ethanol bath and thawed in $37^{\circ} \mathrm{C}$ water bath for three cycles. The cell lyses were incubated in $37^{\circ} \mathrm{C}$ in water bath for $1 \mathrm{~h}$ to degrade genomic DNA, then heated in $95{ }^{\circ} \mathrm{C}$ water bath for 15 min to inactivate DNase. After being centrifuged at $13,600 \mathrm{~g}$ for 5 min under $4^{\circ} \mathrm{C}, 16$ $\mathrm{ml}$ of the upper layer supernatants was collected for RT-PCR.

For reverse transcription (RT), $3.5 \mu \mathrm{l}$ of the supernatants was mixed with $6.5 \mathrm{RT}$ solution A containing $1 \mathrm{X}$ first strand buffer, 2 $\mathrm{mM}$ dNTP, $10 \mathrm{mM}$ DTT, $100 \mathrm{U}$ superscript $\mathrm{TM}^{I I}$ reverse transcriptase, $50 \mathrm{pM}$ random primer. The reaction was lasted for one hour under $37^{\circ} \mathrm{C}$ and terminated at $95^{\circ} \mathrm{C}$ for $5 \mathrm{~min}$. After being diluted for 10 times, $2.5 \mu \mathrm{l}$ RT product were mixed with $16 \mu \mathrm{l} \mathrm{PCR}$ grade water, then with $6.5 \mu \mathrm{l}$ PCR working solution containing 1 X PCR buffer, $1 \mathrm{mM}$ dNTP, 50 pM upstream (5' -AGC TGG CCG TCA ACA TGT CC) and downstream (5' -CCC TTG AGA CTC TTC GAG ACT CC) primers for RHAMM, 2.5U Tag DNA polymerase. PCR was proceeded with the following parameters: $94 \mathrm{oC}$ for $5 \mathrm{~min}$; then $92^{\circ} \mathrm{C}$ for $30 \mathrm{~s}, 60^{\circ} \mathrm{C}$ for $30 \mathrm{~s}$ and $72^{\circ} \mathrm{C}$ for $35 \mathrm{~s}$ for 30 cycles; finally, $75^{\circ} \mathrm{C}$ for $5 \mathrm{~min}$. The PCR products were resolved on an ethidium bromide-stained $1.4 \%$ agarose gel and photographed under UV illumination. The PCR products generated by the paired primers of b-actin[4] were used as the quantitative control.

\section{Protein preparation and Western blot analysis}

Eight to sixteen target fragments were put into the tube containing $25 \mu$ l pre-chilled $2 \mathrm{X}$ Laemmli SDS sample buffer $(0.125$ M Tris-HCl pH 6.8, 4\% SDS, 20\% v/v glycerol and 0.2 M DTT). After being snap frozen in $-85^{\circ} \mathrm{C}$ ethanol bath and thawed in $37^{\circ} \mathrm{C}$ water bath for three times, the samples were heated in boiling water for $5 \mathrm{~min}$. For Western blot hybridization, $50 \mu \mathrm{g}$ protein samples were separated in 6\% SDS-polyacrylamide gel, and then transferred to polyvinylidene difluoride membrane (Amershame, UK). The membrane was blocked with 5\% skimmed milk in PBS and incubated at $25^{\circ} \mathrm{C}$ with the rabbit anti-human RHAMM antibody, then with horseradish peroxidase-conjugated swine anti-rabbit IgG (Dako, Denmark). The bound antibody was detected using the enhanced chemoluminescence (ECL) system (Amersham, UK). The protein obtained from human immortalized keratinocyte line, HaCat, were used as positive control for RHAMM[5].

\section{RESULTS AND DISCUSSION}

The qualitative and/or quantitative genetic events may happen transiently and/or constantly during pathogeneses of human diseases, especially in the carcinogenic processes[6-8]. Therefore, precise genetic evaluation of the cells under normal and abnormal condition is a critical approach in shedding light on the molecular mechanism of the abnormalities. However, unlike the well-controlled in vitro experimental system, the in vivo situation is complicated. One of the major elements is the heterogeneous feature of the tissue specimens. In the case of cancers, normal and/or preneoplastic epithelium, endothelium, stroma tissue as well as immunogenic cells can be observed within and around tumor masses[1],[9]. According to our morphological examination, 18 out of 31 grossly normallike gastric mucosa showed more or less inflammatory reaction (Fig $1 \mathrm{~N}$ ); and six contained preneoplastic regions (Fig 1D). Co-existence of cancer cells with other types of tissues could be observed in most cancer blocks (Fig 1T). In general, the spectrums of gene expression among the nonepithelial tissues and noncancerous gastric mucosa may not be necessarily the same and they should be unequivocally different with the one revealed by malignant cells. As shown in the ICC staining of our current study (Tab 1), the level and distribution of RHAMM protein differ distinctively with the cell types and the grade of the gastric lesions. In order to correlate the results to a defined cell type, the tissue-selective instead of the conventional whole-block RNA and protein preparations are apparently required to minimize the cell-cell contamination.

As the first step to deal with the abovementionedsampling problems, RNA preparation was 

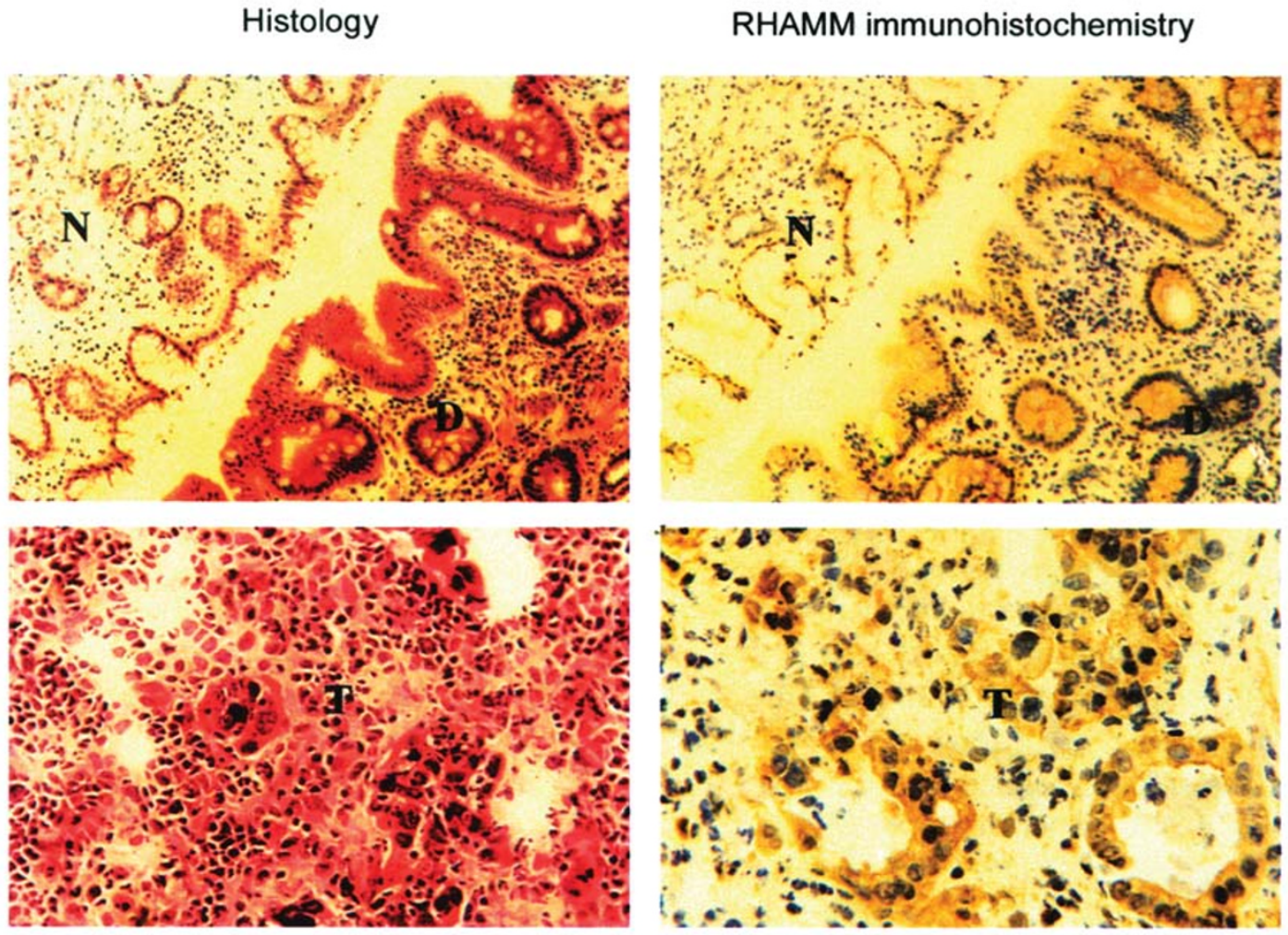

Fig 1. H/E histologic staining (Left) and RHAMM immunohistochemistry (Right) of the frozen sections from a gastric adenocarcinoma. N, grossly normal-like gastric mucosum $(\times 20)$; D, dysplasia Grade II with intestinal metaplasia (×20); T, cancer tissue $(\times 40)$.

Tab 1. RHAMM expression patterns in the selected regions of single tissue blocks

\begin{tabular}{|c|c|c|c|c|c|}
\hline \multirow[t]{2}{*}{ Case } & \multirow[t]{2}{*}{ Selected region } & \multicolumn{2}{|c|}{ ICC Labeling \# } & \multirow{2}{*}{$\begin{array}{c}\text { RT-PCR } \\
\text { Product(s) in bp }\end{array}$} & \multirow{2}{*}{$\begin{array}{c}\text { Western } \\
\text { (kd) }\end{array}$} \\
\hline & & I & $\mathrm{S}$ & & \\
\hline \multirow[t]{2}{*}{$1^{*}$} & Normal & - & - & - & - \\
\hline & Well Diff. Carcinoma & + & + & $600 / 656$ & $45,64,73,90,95$ \\
\hline \multirow[t]{3}{*}{2} & Inflammatory mucosum & + & - & 656 & $45,90,95$ \\
\hline & D III & + & ++ & $600 / 656$ & $45,64,73,90,95$ \\
\hline & Moderately diff. Carcinoma & \pm & ++ & 600 & $45,64,73,95$ \\
\hline \multirow[t]{3}{*}{3} & Normal & - & - & - & - \\
\hline & D II & + & + & $600 / 656$ & $45,90,95$ \\
\hline & Poorly differentiated & + & ++ & $600 / 656$ & $45,64,73,90,95$ \\
\hline \multirow[t]{3}{*}{4} & Atrophic gastritis & + & \pm & 656 & $45,64,90,95$ \\
\hline & D III & + & ++ & $600 / 656$ & $45,64,73,90,95$ \\
\hline & Poorly diff. Carcinoma & ++ & ++ & $600 / 656$ & $45,64,73,90,95$ \\
\hline \multirow[t]{2}{*}{5} & Atrophic gastritis with DII & ++ & + & $600 / 656$ & $45,64,73,95$ \\
\hline & Undifferentiated carcinoma & ++ & ++ & $600 / 656$ & $73,90,95$ \\
\hline \multirow[t]{3}{*}{6} & Atrophic gastritis with DI & + & + & 656 & 45,95 \\
\hline & Moderately diff. Carcinoma & + & ++ & $600 / 656$ & $64,73,95$ \\
\hline & Signet-ring cell carcinoma & ++ & \pm & 656 & 45,95 \\
\hline
\end{tabular}

\# I, intracellular labeling; S, cell surface labeling.

* The data are demonstrated in Fig 1 and 2. D I to III, dysplasia grade I to grade III. 
performed on the specified histological region collected from the frozen section. In comparison with the similar protocols reported previously[6-9], there are several improvements in the sample processing. Firstly, the target fragments are collected directly after cutting and treated without any procrastination. Consequently, potential RNA degradation can be largely avoided. Secondly, paralleled RNA isolations can be performed on the different histological regions in the same section, permitting a more convincing evaluation of gene expression patterns among different cell types (Fig 2). Because of the high yield of this method, only few sections are required in each preparation, making it possible to closely link the RNA data to the morphological and immunohistochemical message revealed from the pre-sliced sections. In comparison with the laser capture microdissection methodology, this method can be performed easily, and is more efficient and economic for common practice. Therefore, it would have a broader application in the basic and, especially, clinical research.

So far, main concerns have been focused on the management of RNA and DNA in tiny tissues or old fixed specimens[8-14] or in the identical histological region[15]. Similar effort for protein preparation has received less attention. Nevertheless, it is necessary to do paralleled RNA and protein studies using the materials obtained from the same cell population. To fill this vital gap for a confidential evaluation of gene expression, cell type-selective protein isolation was followed just after sectioning for RNA preparation. It is demonstrated (Tab 1) that the results of RHAMM RT-PCR and Western blot analyses are matched well and closely coincident with the ones of immunocytochemical staining. Briefly, the normal gastric mucosa were labeled negatively in the immunocytochemical staining (Fig $1 \mathrm{~N}$ ) with neither RTPCR amplification (Fig 2a) nor protein detection (Fig 2b). RHAMM molecules were distributed mainly in cytoplasm of the mucosa with inflammation changes or at early preneoplastic stages (Fig 1D); the RT-PCR products in $656 \mathrm{bp}$ and the proteins in $45 \mathrm{kd}$, $90 \mathrm{kd}$ and $95 \mathrm{kd}$ corresponding to intracellu- lar RHAMM[2], [5] could be detected in the RNA and protein samples extracted selectively from those regions (Fig $2 \mathrm{a}$ and $2 \mathrm{~b}$ ). A close correlation of tumor progression and cell surface RHAMM immunocytochemical labeling (Fig 1T) could be established by showing the co-appearance of extra $600 \mathrm{bp}$ product of mutant variant exon 4 and additional bands in $64 \mathrm{kd}$ and/or 73kd (Fig 2a and 2b). Moreover, the ideology of our work is also feasible to tissue-selective DNA isolation (data not shown). Thus, the novel methods described here may allow us to conduct a comprehensive and more informative study with single tissue block, by combining the slice observations such as pathological examination, immunocytochemical staining and nucleic acid hybridization (ISH) with the techniques for qualitative (DNA) and quantitative (RNA and protein) genetic analyses. It also becomes possible to use one tissue block to check a panel of genetic markers with multiple techniques.

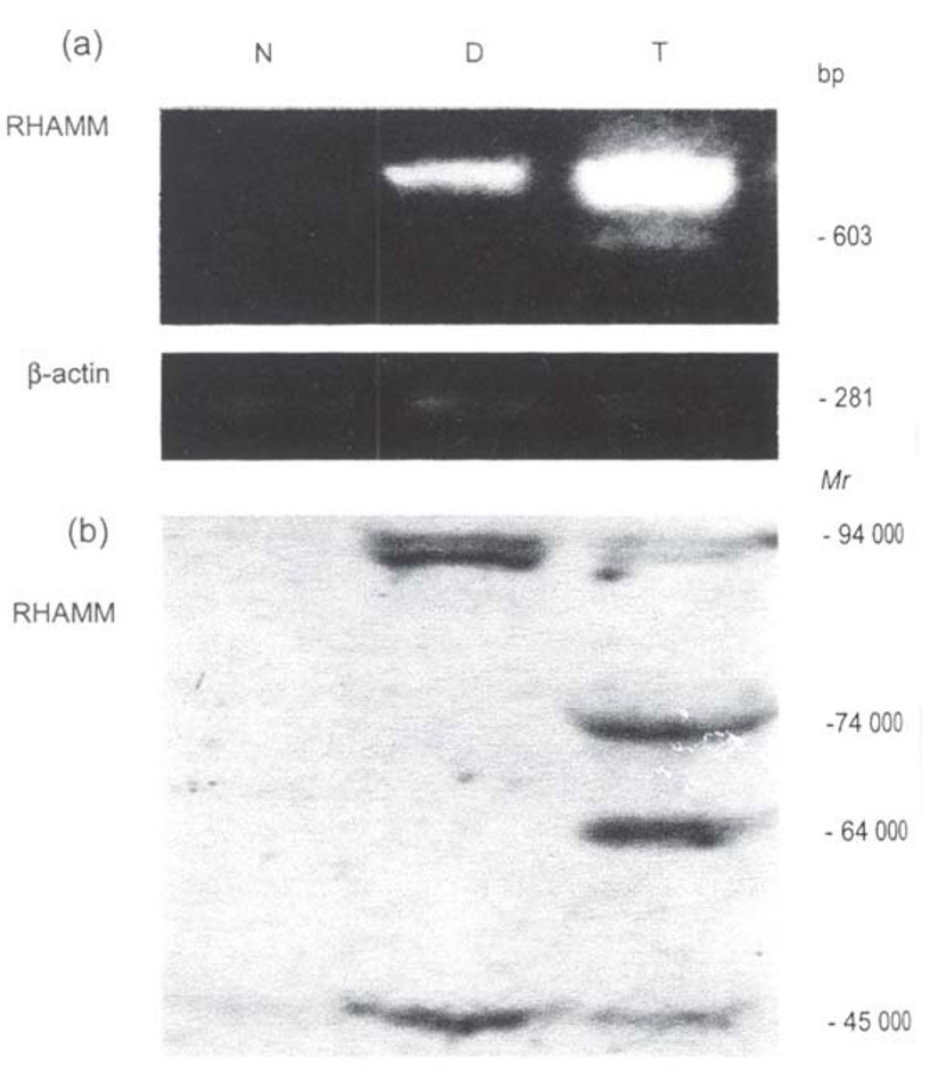

Fig 2. RHAMM RT-PCR amplification (a) and Western blot hybridization (b) using the RNA and protein samples prepared from the histological regions shown in Fig 1. 
An exciting opportunity facing us is identify the entire range of genetic alterations occurred in human abnormalities by genomic and proteomic studies[16-19]. Since those techniques are highly sensitive, cautious morphological evaluation should be performed on the original tissue block to ascertain that the sample RNA and/or protein prepared are extracted from a defined cell type/histological region[16]. Another important issue is to give the tissue samples full uses by high throughput extraction methods, because once going to larger high-density biochips for comparative genomic hybridization (CGH), expression profiling and proteomic analyses, more extracted materials will be consumed. In this regard, a series of tissue-selective nucleic acid and protein preparations described here, especially when it is followed by corresponding frozen tissue arraying, may hold high practical values in the field of genomic studies for screening novel genetic markers associated with the target abnormality.

\section{ACKNOWLEDGMENT}

This work was supported in part by National Natural Science Foundation of China (No. 39470767 and No. 396101300419) and by a special grant from Liaoning Provincial Committee for Science and Technology, China (No. 963010).

\section{REFERENCES}

[1] Li H, Liu N, Guo L, Liu J. Frequent expression of soluble Fas and Fas ligand in Chinese stomach cancers and their potential implication. Int J Mol Med 2000; 5:473-6.

[2] Assmann V, Marshall JF, Fieber C, Hofmann M, Hart IR. The human hyaluronan receptor RHAMM is expressed as an intracellular protein in breast cancer cells. 1998; J Cell Sci 111:1685-94.

[3] Li H, Liu J, Hofmann M, Hamou, MF, de Tribolet N. Differential CD44 expression patterns in primary brain tumours and brain metastases. Brit J Cancer 1995; 72: 160-4.

[4] Liu J, Guo L, Luo Y, Li JW, Li H. All trans retinoic acid suppresses in vitro growth and down regulates LIF expression as well as telomerase activity in human medulloblastoma cells. Anticancer Res 2000; 20:4681-6.

[5] Li H, Guo L, Li JW, Liu N, Qi R, Liu J. Differential expression of hyluronan receptors CD44 and RHAMM in stomach cancers and their relevance with tumor progression. Int $\mathbf{J}$ Oncol 2000; 17:927-32.

[6] Cottage A, Dowen S, Roberts I, Pett M, Coleman N, Stanley M. Early genetic events in HPV immortalised keratinocytes. Genes Chromosomes Cancer 2001; 30:72-9.

[7] Bertucci F, Houlgatte R, Benziane A, et al. Gene expression profiling of primary breast carcinomas using arrays of candidate genes. Hum Mol Genet 2000; 9:2981-91.

[8] Clausen OP, Andersen SN, Stromkjaer H, et al. A strategy combining flow sorting and comparative genomic hybridization for studying genetic aberrations at different stages of colorectal tumorigenesis in ulcerative colitis. Cytometry 2001; 43:46-54.

[9] Park CC, Bissell MJ, Barcellos-Hoff MH. The influence of the microenvironment on the malignant phenotype. Mol Med Today 2000; 6:324-29.

[10] Jiang YH, Davidson LA, Lupton JR, Chapkin RS. A rapid RT-PCR method for detection of intact RNA in formalin-fixed paraffin-embedded tissues. Nucleic Acids Res 1995; 23:3071-72.

[11] To MD, Done SJ, Redston M, Andrulis IL. Analysis of mRNA from microdissected frozen tissue sections without RNA isolation. Am J Pathol 1998; 153:47-51.

[12] Gandini O, Celi FS, Magnanti M, et al. A rapid, simple, and inexpensive step facilitates RNA extraction from whole blood cells. Lab Invest 1999; 79:1731-2.

[13] Li H, Lee GH, Cui LX, Liu J, Nomura K, Ohtake K, Kitagawa T. Absence of H-ras point mutation at codon 12 in N-methyl-N-nitrosourea-induced hepatocellular neoplasms in the rat. J Cancer Res Clin Oncol 1990; 116:331-5

[14] Sarkar FH, Valdivieso M, Borders J, et al. A universal method for the mutational analysis of K-ras and p53 gene in non-small-cell lung cancer using formalin-fixed paraffin-embedded tissue. Diagn Mol Pathol 1995;4:26673.

[15] Burton MP, Schneider BG, Brown R, Escamilla-Ponce N, Gulley ML. Comparison of histologic stains for use in PCR analysis of microdissected, paraffin-embedded tissues. Biotechniques 1998; 24:86-92.

[16] Brown PO, Hartwell L. Genomics and human diseasevariations on variation. Nat Genet 1998; 18:91-3.

[17] Hacia JG, Fan JB, Ryder O, et al. Determination of ancestral alleles for human single-nucleotide polymorphisms using high-density oligonucleotide arrays. Nat Genet 1999; 22:164-7.

[18] Rimm DL. Molecular biology in cytopathology: current applications and future directions. Cancer 2000; 90:1-9.

[19] Richter J, Wagner U, Kononen J, et al. High-throughput tissue microarray analysis of cyclin $\mathrm{E}$ gene amplification and overexpression in urinary bladder cancer. Am J Pathol 2000; 157:787-94. 